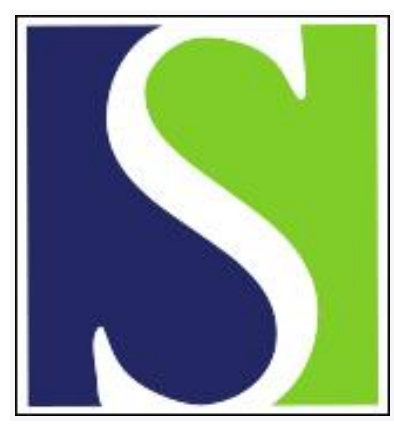

Scand J Work Environ Health 1991;17(6):414-419

https://doi.org/10.5271/sjweh.1681

Issue date: Dec 1991

Back disorders and health problems among subway train operators exposed to whole-body vibration.

by Johanning $E$

Affiliation: Department of Community Medicine, Mount Sinai School of Medicine, New York, NY 10029-6574.

This article in PubMed: www.ncbi.nlm.nih.gov/pubmed/1838616 


\title{
Back disorders and health problems among subway train operators exposed to whole-body vibration
}

\author{
by Eckardt Johanning, $M D^{1}$
}

\begin{abstract}
JOHANNING E. Back disorders and health problems among subway train operators exposed to wholebody vibration. Scand J Work Environ Health 1991;17:414-9. Back disease associated with whole-body vibration has not been evaluated for subway train operators. A recent study demonstrated that this group is exposed to whole-body vibration at levels above the international standard. To investigate this risk further, a self-administered questionnaire survey was conducted among subway train operators $(\mathrm{N}=492)$ and a similar reference group $(\mathrm{N}=92)$. The operators had a higher prevalence than the referents in all aspects of back problems, particularly for cervical and lower back pain. In a multiple logistic regression model, the odds ratio for sciatic pain among subway train operators was 3.9 (95\% CI $1.7-8.6)$; the operators also had a higher risk of hearing-related problems (odds ratio 3.2, $95 \% \mathrm{CI} 0.6-17.4$ ) and of gastrointestinal problems (odds ratio 1.6, $95 \%$ CI 1.1-2.5). Although a cumulative dose-response relationship could not be statistically demonstrated, the findings appear to be related to exposure to wholebody vibration and inadequate ergonomic conditions.
\end{abstract}

Key terms: adverse health effects, epidemiology, ergonomics, musculoskeletal disorders, rail vehicle, spine.

Musculoskeletal disorders of the back are a leading cause of occupational injuries and disability in industrialized countries. In 1987 disorders related to repeated trauma (repetitive work procedures) accounted for about $40 \%$ of all reported occupational illnesses in private industry in the United States, and the numbers are increasing. The total compensable cost for lowback pain in the United States was estimated in 1986 to be USD 11.1 billion $(1,2)$. Several occupational causes and risk factors for back problems have been identified, such as lifting, bending, twisting, and highly repetitive tasks (3).

Direct, long-term whole-body vibration, stemming from engines and vehicles, has been recognized as a mechanical stress factor for accelerated degenerative spine disease, back pain, and prolapsed disks (4-8). Poor body posture, inadequate seat support, and muscular fatigue of the drivers have been described as cofactors $(9,10)$.

A recent evaluation of exposure to whole-body vibration in the New York City subway system revealed vertical and lateral vibration at levels clearly exceeding the 8-h "fatigue decrease proficiency" limits set by the International Organization for Standardization (11). To investigate a possible correlation between the frequent back complaints of subway train operators and their exposure to whole-body vibration, a comparative cross-sectional survey was conducted.

\footnotetext{
1 Department of Community Medicine, Division of Environmental and Occupational Medicine, Mount Sinai School of Medicine, New York, New York, United States.
}

Reprint requests to: Dr E Johanning, Mount Sinai School of Medicine, Division of Environmental and Occupational Medicine, 1 Gustave Levy Place, New York, NY 10029-6574, USA.

\section{Subjects and methods}

As of the winter of 1989 the New York City Transit Authority employed 2910 subway train operators and 507 tower operators (switch board operators). Both of these job titles are "end-promotional" positions within the Metropolitan Transit Authority, and thus both groups are considered to be very stable, with a low turnover rate. The tower operators were chosen for the study as a comparison group of workers unexposed to whole-body vibration because their demographic characteristics, job histories, and job responsibilities are very similar to those of subway train operators. Both groups are exposed to sustained sitting, and neither group is exposed to other relevant back loading factors at work. Initially, in this study, the questionnaire forms were distributed haphazardly. Because this first collection process did not achieve the desired return results, a second computer-generated random sample was selected for a postal questionnaire survey. Response rates of $53 \%$ for the subway train operators and $60 \%$ for the tower operators were achieved. Responses to each sampling were statistically compared to assess potential differences. No differences were found, and therefore the respondents to the two surveys were merged $(12,13)$. By the end of May 1990 , 832 fully completed questionnaires had been returned for processing. Subjects of both groups $(\mathrm{N}=248)$ with a history of back problems or previous occupational whole-body vibration exposure (ie, bus or truck driver) prior to entering their current job title were excluded to reduce the introduction of bias due to a condition which was not associated with the current job title or outcome of interest.

The job-health questionnaire was based on previously described questionnaires utilized in Scandina- 
via and central Europe for vehicle operators and railroad personnel. It included questions about the work conditions and general health complaints of the respondents (14-16). Questions related to back symptoms were adopted from a screening manual developed by a team of cumulative trauma disorder researchers (17) for occupational epidemiologic surveys. Respondents were asked about history, location, timing, and severity of the back complaint symptomatology. Sciatic pain was computed by a combination of different responses and defined as recurrent (more than three times per year) or lasting (more than one week) pain in the lower back and radiating down the leg to below knee level. Recurrent back pain was defined as pain lasting more than one week and occurring more than three times in the past year. Current low-back pain was defined as pain at the time of the survey completion. To reduce over- and underreporting due to memory decay and "telescoping biases," the questions were limited to a period of one year before the survey. Respondents were asked to rate complaints on an analogue fivepoint scale with opposing adjectives ("never" to "always") (18). This technique was validated with a selfadministered questionnaire (19).

A total of 584 questionnaires were analyzed, 492 from subway train operators and 92 from tower operators. The mean age was 41.5 (SD 10) years, and the mean employment duration was 9.8 (SD 7.4) years. Males were in the majority in both job titles (table 1). Most of the subway train operators had worked previously for the Transit Authority as conductors, car cleaners, or railroad clerks. Only $7 \%$ had entered their position as a subway train operator directly from outside the Transit Authority. The tower operators showed a similar pattern. A nonspecific question regarding general health was answered without significant differences. This result indicated a similar background level of health concerns among the comparison groups. For subway operators, seat exposure to whole-body vibration is considered the most important risk factor for spinal problems. Representative, simultaneous triaxial measurements on the seat pad were conducted according to available standards (11, $20,21)$. The average weighted acceleration in the lateral direction was $0.26 \mathrm{~m} / \mathrm{s}^{2}$ [or $6 \mathrm{~h}$, fatigue decreased proficiency exposure limits (FDP-EL)], the vertical was $0.37 \mathrm{~m} / \mathrm{s}^{2}$ (or $6 \mathrm{~h}$ and $5 \mathrm{~min}$, FDP-EL). The vector sum was $0.55 \mathrm{~m} / \mathrm{s}^{2}$ (or $3 \mathrm{~h}$ and $44 \mathrm{~min}$, FDP-EL). High acceleration peaks in critical human body resonance were present in all of the tested samples. A typical workshift in the cab lasts seven or more hours per day. There have been no major structural improvements made in the subway system over the past four decades. Therefore, the duration of employment as a subway train operator functioned as a proxy for the cumulative exposure dose of whole-body vibration.

A data base (22) and the SYSTAT statistical program (23) were used to process the data on a personal computer and calculate routine statistics. Multiple logistic regression models were used to adjust for possible confounders and to estimate the log of the odds ratio for different categories of exposure.

\section{Results}

The subway train operators had a higher prevalence of self-reported complaints in every category when compared with the reference group; nearly threefourths of the subway train operators complained of recurrent neck, upper back, or lower back pain - or a combination of these - versus about one-half of the referents. In particular low-back pain was mentioned by $56 \%$ of the subway train operators versus $36 \%$ for the tower operators. Neck pain was also rated relatively higher with $31 \%$ versus $24 \%$, respectively. Lower or upper back pain at the time of the survey was mentioned by $41 \%$ of the subway train operators versus $25 \%$ of the tower operators (figure 1). Lower back problems were characterized predominantly as "pain" or "stiffness," for both job titles. Other symptoms included cramping, pins and needles or numbness in the lower back and/or legs, and burning or swelling. Sciatic pain was assessed through the combination of responses that has already been described. In the logistic regression model the odds ratio for sciatic pain among subway train operators was 3.9 (95 \% CI 1.7-8.6) when confounders and independent variables [age, age ${ }^{2}$ [the quadratic term was used to correct for an age-dependent effect (24)], gender, job title and employment duration\} were controlled for. The duration of employment in the present job title did not significantly change the likelihood of developing sciatic pain for any job title. There was a significantly greater association for sciatic pain for respondents who tended to sit more often or complain more frequently about vibration at work. The medication usage rate to relieve back pain was lowest among the tower operators. Worktime loss due to back problems showed no significant differences. Only a few individuals in each job category indicated long (one month or more) worktime losses. However, the subjects with 11 or more years on the job and sciatic symptoms had a longer sick leave rate due to their back problems. The subway train operators had the highest rate of back injury reports, with $10 \%$ versus $1 \%$

Table 1. Demographics of the respondents to the New York City Transit Authority job-health survey of subway train operators.

\begin{tabular}{lcccccc}
\hline & $\begin{array}{c}\text { Male } \\
(\%)\end{array}$ & Age (years) & & $\begin{array}{c}\text { Duration of } \\
\text { employment } \\
\text { (years) }\end{array}$ \\
\cline { 2 - 3 } & & Mean SD & & Mean & SD \\
\hline $\begin{array}{l}\text { Subjects } \\
(\mathrm{N}=492)\end{array}$ & 95 & 39.8 & 11.8 & & 10.4 & 11.7 \\
$\begin{array}{l}\text { Referents } \\
(\mathrm{N}=92)\end{array}$ & 75 & 44.3 & 10.4 & & 7.7 & 7.2 \\
\hline
\end{tabular}




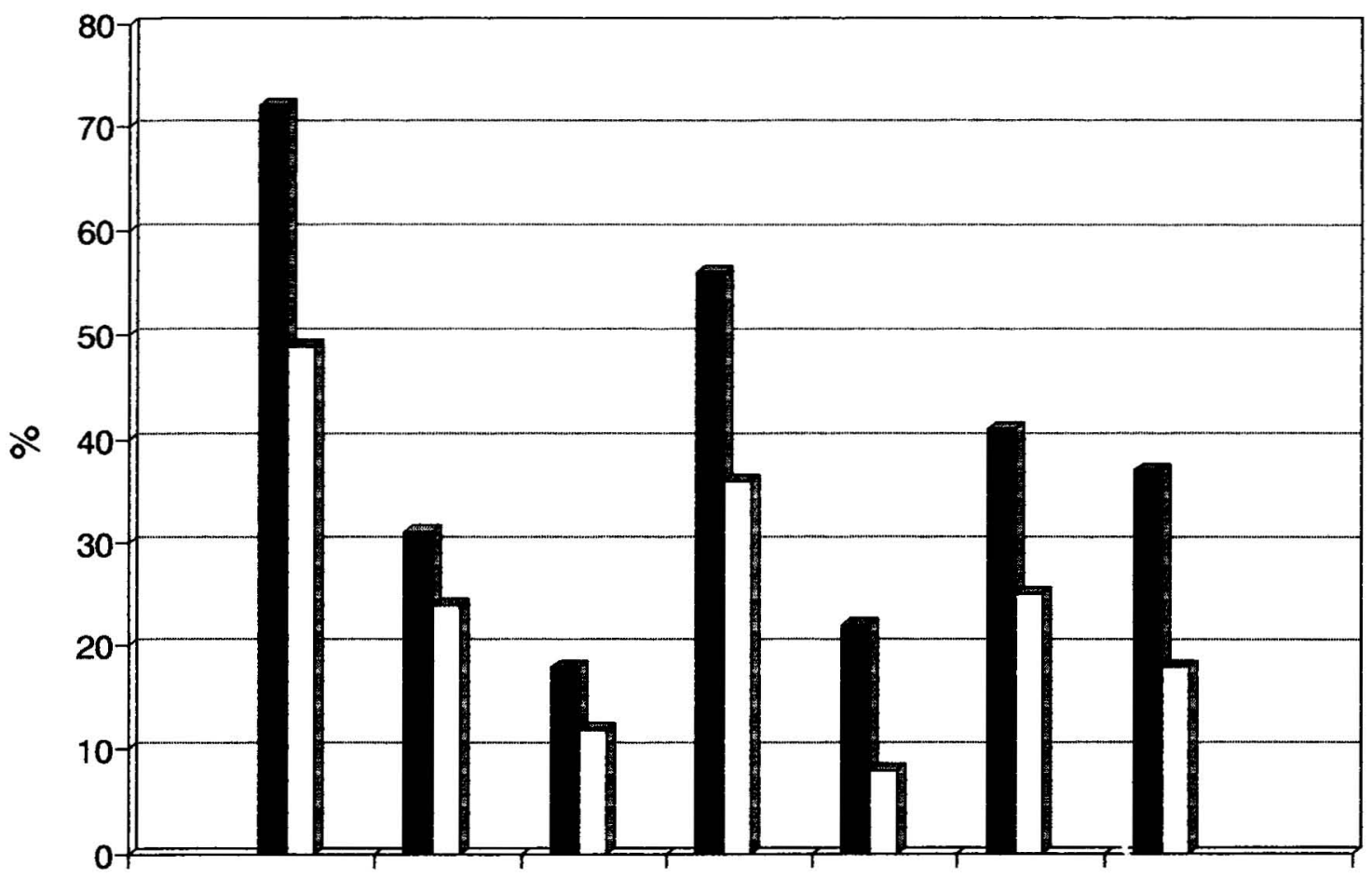

Any back pain. Pain: Neck, Upper back, Lower back. Sciatica. LBP, now. LBP, recurrem.

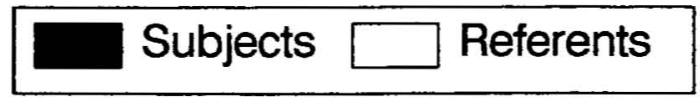

Figure 1. Results of the job-health survey of the type and location of back problems experienced by subway train operators within the past year of the survey. Respondents with a history of back problems prior to entering the current exposure category (job title) were excluded. (LBP = low-back pain)

Table 2. Results of logistic regression analyses of the jobhealth survey of subway train operators. $(95 \% \mathrm{Cl}=95 \%$ confidence interval)

\begin{tabular}{lccc}
\hline Variable & Odds ratio & $95 \% \mathrm{Cl}$ & P-value \\
\hline $\begin{array}{l}\text { Sciatica pain } \\
\text { Indigestion/gastro- }\end{array}$ & 3.9 & $1.7-8.6$ & $<0.03$ \\
intestinal problems & 1.6 & $1.1-2.5$ & $<0.05$ \\
Hearing & 3.2 & $0.6-17.4$ & $<0.005$ \\
\hline
\end{tabular}

Table 3. Results of the work environment factors in the jobhealth survey of subway train operators.

\begin{tabular}{lcc}
\hline Response & $\begin{array}{c}\text { Subjects } \\
\mathbf{( N = 4 9 2 )}(\%)\end{array}$ & $\begin{array}{c}\text { Referents } \\
(\mathrm{N}=92) \\
(\%)\end{array}$ \\
\hline Cab space too small & 90 & 32 \\
Seat adequate & 17 & 31 \\
Need more relay/break time & 86 & 58 \\
\hline
\end{tabular}

among the tower operators. Twice as many of the subway train operators $(15 \%)$ as compared with the tower operators $(7 \%)$ reported that they had sought professional help because of back complaints or had a medically confirmed back problem, such as disk hernia- tion, strained or pulled muscle, curved spine, or blunt trauma.

In addition the respondents were asked to rate work factors and conditions. The responses were stratified into seniority subgroups of $1-10$ or $\geq 11$ years on the job. The subway operators and the referents sit most of the time while they are working, and there were no significant differences between the job titles for sitting at work. More than half of both seniority groups of the subway train operators indicated that they were sometimes bothered by vibration on the job. The respondents with sciatic pain complained significantly more frequently about vibration. The senior subway operators complained more often about inadequate and poor room/cab temperature control. Between the two job categories there was no statistically different rating for drafty conditions.

In a multiple logistic regression analysis of selected outcome variables, the subway train operators had a significantly higher health risk compared with the referents. The hearing problems of the subway train operators correlated with their noise complaints and employment duration when the subway train operators and referents were compared. The relative risk (RR) for the subway train operators was threefold (RR 3.2) 
that of the tower operators. The relative risk for the outcome indigestion or stomach problems was 1.6 (table 2).

Only $17 \%$ of all the subway train operators noted that the operator seat in the subway cab was adequate for their job, and $90 \%$ would like more cab space. The average space of the floor of the subway cab is about $2 \mathrm{~m}^{2}$ (ie, about one-tenth of the workspace of the tower operators). All of the subway train operators indicated that they were frequently under time pressure. The time pressure complaint rate was significantly higher than in the reference group. A need for more break or relay time was noted by $86 \%$ of the subway operators (table 3 ). The subway train operators did not record any particular vision problems during exposure, and no significant differences in the prevalence of headache complaints were measured. There was no differential reporting of exhaustion among the two job titles, although the odds ratio in the regression model for women was 2.6 .

\section{Discussion}

The principal finding in the study was a considerably higher prevalence of various types of back symptoms among the subway operators as compared with referents. The subway train operators had a nearly fourfold risk of developing sciatic pain. The subway train operators predominately reported lower back and neck pain. They also had a significantly higher risk of indigestion or gastric problems and noise-related hearing problems. The prevalence of complaints about the work conditions (poor climatic control of the cab among the more senior subway train operators, intense noise, inadequate seat and cab design, and limited cab space) was significantly higher for the subway train operators. A perceived stressful work schedule was overwhelmingly criticized by the subway train operators, most of whom complained about constant time pressure and lack of recovery time. The respondents with sciatic pain complained more frequently about vibration. There was no true variation in vibration exposure according to the exposure measurements, and, due to the fact that drivers operate various train types and use different routes during their career, it may be that those with back problems are more sensitive to vibration or that other factors unrelated to exposure influence their responses. Overall, the results of the job-health questionnaire agree with previous reports on potential effects of whole-body vibration.

Care was taken to avoid possible selection biases and to deal appropriately with confounders. Yet some of the factors were beyond control. The response rate in the postal sample was relatively low, being 53$60 \%$. This rate is comparable to that of other postal surveys in the United States (25). However, it may introduce a sampling bias, overrepresenting respondents with conditions which favor participation in the survey. From a sample of nonrespondents it was learned that some transit workers were generally skeptical about the utility of surveys, and a job-health survey of transit workers in particular, or a negative attitude existed against any solicitations of opinions. Three to six percent of the postal survey candidates were inaccessible by any means.

Although cross-sectional surveys have their unique methodological limitations, certain advantages of this method have been noted by Monson (26). For example, within a certain context, inferential statements can be made on the basis of plausibility and already existing knowledge about disease pathogenesis. In the present study a claim for a causal relationship between the high prevalence of back problems among subway train operators and whole-body vibration received support from previous epidemiologic reviews $(5,7,27)$.

The risk of the outcome sciatic pain did not increase with the duration of employment when the subway train operators and referents were compared. The explanation may either be that the survey was not sufficiently sensitive or that severe back pain forces subway train operators to migrate out of the job, leaving those operators with less symptomatic backs. This selfselection process has been described earlier for bus drivers $(28,29)$. Dutch investigators, who studied selfreported back pain among tractor drivers and the relationship to an estimated vibration dose, also found that the odds ratio for the more severe type of back pain did not increase with the vibration dose (30). A subsequent investigation of the subjects who left such work may be of merit.

There are no comparative studies of subway operators available concerning their exposure situation, subjective rating of physical stress factors, and health problems, although public transportation personnel and drivers are receiving more and more attention from investigators because of their preeminent rate of chronic health problems and early disability. In one recent German morbidity report it was found that, on the average, mass transit bus, trolley, and subway train operators were unable to operate their vehicle after a mean employment of 21 years and a mean age of 49 years. The primary reasons were cardiovascular diseases, musculoskeletal (particularly back disorders), psychovegetative syndrome, and gastrointestinal diseases (31). Other German investigators have described similar complaints about ergonomic conditions and work organization $(14,32)$. Nonetheless, in these studies no exposure measurements or clinical evaluations were done.

The few studies of railroad engineers and personnel in other European countries also found higher rates of back disorders, cardiovascular disease, and digestive and hearing problems. The first report came from France as early as $1954(15,16,33,34)$. A high prevalence of cervical spondylosis and general spinal degenerative changes were found for male Yugoslavian railroad workers. Horizontal and vertical vibrations 
stemming from the track, train speed, and road level were noted to be possible causes (35).

Biomechanical vibration can affect the muscle, ligaments, discs, and skeletal structure of the spine and result in sciatica or other neurological complications $(36,37)$. One recent study of construction workers reported that progressive degenerative spinal changes were associated with an increased risk of sciatic pain $(38,39)$.

There is currently no known disorder that is caused solely by whole-body vibration. Among tractor drivers, truckers and interstate bus drivers, crane or earthmoving equipment operators, and helicopter pilots primarily exposed to vertical vibration a high rate of back complaints and abnormal radiographs of the spine (50 to $80 \%$ ) have been reported $(9,10,40-42)$. On the basis of this study the higher prevalence of sciatic pain among subway train operators may be explained by whole-body vibration. Considering the previously reported higher vibration exposure levels in the vertical direction in other vehicle types, the nearly fourfold risk of sciatic pain among subway operators in the present study may be related to the relatively high lateral vibration combined with vertical vibration. Some previous reports of a high prevalence of back pain among professional drivers was associated with higher vertical accelerations than measured in our study. However, simultaneous multiaxis vibration may result in increased cumulative biomechanical stress when compared with predominantly unidirectional vibration and may have more than an additive effect. Both biomechanical data and epidemiologic studies on lateral or combined vibration loads on the spine are rare. Our findings indicate a need for further investigations of multiaxis vibration.

Ambient noise levels of 80 to $90 \mathrm{~dB}(\mathrm{~A})$, with peak levels of 100 to $110 \mathrm{~dB}(\mathrm{~A})$ have been measured in subways (43). An interaction between high noise levels and whole-body vibration may increase the risk of vibration effects in addition to creating a higher likelihood of hearing problems among subway train operators $(44,45)$.

A further clinical evaluation of subway operators' backs and magnetic resonance imaging of the spine to detect and correlate possible morphological and biochemical changes seems indicated. Work organizational and ergonomic improvements should be considered to reduce the health risks of subway operators.

\section{Acknowledgments}

I wish to thank the Transport Workers Union of America, Local 100 (New York City) for their cooperation and Dr P Landrigan and Dr C Schechter for their assistance and critical review of the manuscript.

\section{References}

1. Bureau of National Affairs Inc (BNA). Back injuries: costs, causes and prevention. Washington, DC: BNA, 1988.

2. Webster B, Snook S. The cost of compensable low back pain. J Occup Med 1990;32:13-6.

3. Pope MH, Frymoyer JW, Andersson G, ed. Occupational low back pain. New York, NY: Praeger 1984; $101-36$.

4. Dupuis H, Zerlett G. Whole-body vibration and disorders of the spine. Int Arch Occup Environ Health 1987;59:323-36.

5. Hulshof C, van Zanten B. Whole-body vibration and low-back pain. Int Arch Occup Environ Health 1987; 59:205-20.

6. Kelsey JL, Hardy RJ. Driving of motor vehicles as a risk factor for acute herniated lumbar intervertebral disc. Am J Epidemiol 1975;102:63.

7. Seidel H, Heide R. Long-term effects of whole-body vibration: a critical survey of the literature. Int Arch Occup Environ Health 1986;58:1-26.

8. Allgemeine Unfallversicherungsanstalt. IVSS 1989 , Schlußbericht: Vibration am Arbeitsplatz, 3.Internationales Kolloquium der Internationalen Sektion der IVSS zur Forschung über die Verhütung von Arbeitsunfällen und Berufskrankheiten. Wien: Allgemeine Unfallversicherungsanstalt, 1989.

9. Griffin MJ. Handbook of human vibration. London: Academic Press, 1990.

10. Dupuis H, Zerlett G. Forschungsbericht Ganz-KörperSchwingungen: Beanspruchung des Menschen durch mechanische Schwingungen. Bonn: Schriftenreihe des Hauptverbandes der gewerblichen Berufsgenossenschaften e.V., 1984. (English publication: The effects of whole-body vibration. Berlin: Springer Verlag, 1986:7126.)

11. Johanning E, Wilder D, Landrigan P, Pope $\mathbf{M}$. Wholebody vibration exposure in subway cars and review of adverse health effects. J Occup Med 1991;33(5):605-12.

12. Kleinbaum DG, Morgenstern H, Kupper LL. Selection bias in epidemiological studies. Am J Epidemiol 1981; 113(4):452-63.

13. Hochstim JR, Athanasopoulos DA. Personal follow-up in a mail survey: its contribution and its cost. Publ Opin Q 1970;34:69-81.

14. Bundesanstalt für Arbeitsschutz und Unfallforschung Dortmund. Verbesserung der Arbeitsbedingungen von Straßenbahn-und Busfahrern (-innen). Dortmund: Bundesanstalt für Arbeitsschut $z$ und Unfallforschung, 1983. (Nr 33 und 37.)

15. Hannunkari I, Heino M, Järvinen E, et al. Arbeitsbedingungen und Gesundheit der Lokomotivführer der Finnischen Staatseisenbahn. Z Gesamte Hyg Ihre Grenzgeb $1977 ; 10: 734-7$.

16. Hannunkari I, Järvinen E, Partanen T. Work conditions and health of locomotive engineers: II. questionnaire study, mortality and disability. Scand J Work Environ Health 1978;4(suppl 3):15-28.

17. Silverstein BA, Fine LJ. Evaluation of upper extremity and low back cumulative trauma disorders - a screening manual. Ann Arbor, MI: Center for Ergonomics, University of Michigan, 1984.

18. Bond $\mathbf{A}$, Lader $\mathbf{M}$. The use of analogues scales in rating subjective feelings. Br J Med Psychol 1974;47:211-8.

19. Baecke JAH, Burema J, Frijters JEN. A short questionnaire for the measurement of habitual physical activity in epidemiological studies. Am J Clin Nutr 1982;36: $936-42$.

20. International Organization for Standardization (ISO). Evaluation of human exposure to whole-body vibration: part 1: general requirements. Geneva: ISO, 1985. (ISO 2631.)

21. Verein Deutscher Ingenieure. Einwirkungen mechani- 
scher Schwingungen auf den Menschen [Effect of mechanical vibrations on human beings]. Düsseldorf: VDI-Verlag, 1987:1-6. (VDI-Publ No 2057.)

22. Borland International. PARADOX 3.0 (computer software). Scotts Valley, CA: Borland International, 1988.

23. Systat. SYSTAT 4.0 (computer software). Evanston, IL: Systat, 1989.

24. Biering-Sorenson $\mathbf{F}$. Low back trouble in a general population of 30-, 40-, 50- and 60-year old men and women. Dan Med Bull 1982;29:289-99.

25. Kelsey JL, Thompson WD, Evans AS. Methods in observational epidemiology. New York, NY: Oxford University Press, 1986. (Monographs in epidemiology and biostatistics; vol 10.)

26. Monson RR. Occupational epidemiology. 2nd edition. Boca Raton, FL: CRC Press, 1990.

27. Troup JDG. Driver's back pain and its prevention a review of the postural, vibratory and muscular factors, together with the problem of transmitted roadshock. Appl Ergon 1978;9:207-14.

28. Garbe C. Gesundheitszustand und gesundheitliche Risiken von Linienbusfahrern in Berlin (West). Berlin: Sozialmedizin und epidemiologische Berichte des Bundesgesundheitsamt, 1981.

29. Backman AL, Järvinen E. Turnover of professional drivers. Scand J Work Environ Health 1983;9:36-41.

30. Boshuizen HC, Bongers PM, Hulshof CTJ. Self-reported back pain in tractor drivers exposed to wholebody vibration. Int Arch Occup Environ Health 1990; 62:109-15.

31. Haas J, Petry H, Schühlein W. Untersuchung zur Verringerung berufsbedingter Gesundheitsrisiken im Fahrdienst des öffentlichen Personennahverkehrs. Dortmund: Schriftenreihe der Bundesanstalt für Arbeitsschutz, 1989. (Fb 597).

32. Karmaus W, Osterholz U. Herausforderungen und Perspektiven der Bekämpfung rheumatischer Erkrankungen. In: Argument Verlag. Argument-Sonderband AS 182 - Chronische Krankheit: ohne Rezepte. Hamburg: Argument Verlag, 1990.

33. Louyot $P$, DeRen $G$, Jouret. Le rachis des chaufferus de locomotives. Lille: Association de Medicine du Travail du Nord, 1954

34. Netterstrom B, Paludan LS, Laursen P. Health of en- gine drivers. Ugskr Laeger 1983;145:1969—74.

35. Arnautova-Bulat $S$. On the possible effects of vibration on the spine of railwayman. Arh Hig Rada Toksikol 1979;30:259-266.

36. Brinkmann P, Pope MH. Effects of repeated loads and vibration. In: Weinstein JN, Wiesel SW, ed. The lumbar spine. Philadelphia, PA: Saunders Company, 1990: $171-87$.

37. Junghanns H. Die Wirbelsäule in der Arbeitsmedizin. Stuttgart: Hippokrates, 1979:I-III.

38. Riihimäki H, Wickström $G$, Hänninen $K$, Mattsson $T$, Waris $P$, Zitting A. Radiographically detectable lumbar degenerative changes as risk indicators of back pain: a cross-sectional epidemiologic study of concrete reinforcement workers. Scand J Work Environ Health 1989; $15: 280-5$.

39. Riihimäki H, Wickström $\mathrm{G}$, Hänninen $\mathrm{K}$, Luopajärvi $T$. Predictors of sciatic pain among concrete reinforcement workers and house painters - a five-year followup study. Scand J Work Environ Health 1989;15:41523.

40. Heide R. Zur Wirkung langzeitiger beruflicher Ganzkörpervibrationsexposition [Dissertation]. Berlin: Humboldt Universität, 1977.

41. Heliövaara $M$, Knekt $P$, Aromaa $A$. Incidence and risk factors of herniated lumbar intervertebral disc or sciatica leading to hospitalization. J Chronic Dis 1987;40: 251-8.

42. Heliövaara M. Occupation and risk of herniated lumbar intervertebral disc or sciatica leading to hospitalization. J Chronic Dis 1987;40:259-64.

43. Harris CM, Aitken BH. Noise in subway cars. Sound Vib 1971;2: 12-4

44. Seidel H, Richter J, Kurerov NN, Schajpak EJ, Bluthner R, Erdmann U, Hinz B. Psychophysical assessment of sinusoidal whole-body vibration in z-axis between 0.6 and $5 \mathrm{~Hz}$ combined with different noise levels. Int Arch Occup Environ Health 1989;61:413-22.

45. Smith A. Noise, performance efficiency and safety. Int Arch Occup Environ Health 1990;62:1-5.

Received for publication: 27 March 1991 